\title{
Myth and ideology in Consumer Culture Theory
}

\author{
Authors:
}

James A Fitchett. Professor of Marketing and Consumption, University of Leicester School of Management, University Road, Leicester, LE1 7RH, UK. Email: j.fitchett@le.ac.uk

Georgios Patsiaouras, Lecturer in Marketing, University of Leicester School of Management, University Road, Leicester, LE1 7RH, UK. Email: g.patsiaouras@le.ac.uk

Andrea Davies. Senior Lecturer in Marketing, University of Leicester School of Management, University Road, Leicester, LE1 7RH, UK. Email: a.davies@le.ac.uk

\begin{abstract}
The special issue of Marketing Theory (2013) on Consumer Culture Theory (CCT) updates and restates the main aims and controversies in CCT as well as offering a number of novel interpretations on the history and possible future direction of the movement. While the anchor paper from Thompson et al. (2013) is notable for the invocation of Bakhtin's concept of Heteroglossia, its main significance is as a reply to on-going critiques of the CCT project. In this commentary article we highlight the common tendency among critics to emphasise the paradigmatic and institutional basis for CCT as residing in the context of academic discourse. These accounts utilise what Coskuner-Balli (2013) discusses as the mobilization of cultural myths. One consequence of this process of retelling the CCT creation narrative is that it diverts and obscures other ideological readings of CCT. We highlight what we understand as the underlying neoliberal sentiment at the centre of the CCT project. A neoliberal perspective repositions some of the main criticisms of CCT, especially those regarding the overemphasis on consumer subjectivities.
\end{abstract}

\section{Introduction}

Real problems of finding adequate outlets for surplus capital began to emerge after 1980, even with the opening up of China and the collapse of the Soviet bloc. The difficulties were in part resolved by the creation of fictitious markets where speculation in asset values could take off unchecked by any regulatory apparatus. Where will all this investment go now? (Harvey, 2011: 216-7)

There are a number of arguments to explain why the development and promotion of critical research agendas in marketing and consumer research have not been easy to achieve and sustain. From several perspectives the challenge arises from the fact that marketing and consumer research have maintained an underlying commitment to micro-level, managerialist and functional concerns and that this has severely limited the possibility of using a marketing research agenda to examine broader social, cultural and macro-level considerations. Consumer Culture Theory (CCT) (Arnould and Thompson 2005) is one of the most recent, and by many assessments, the most successful movement in consumer research to present a coherent and substantial alternative to what its advocates define as a dominance of microeconomic theory and cognitive psychology inspired approaches. The architects of the CCT movement have consistently argued that it is beneficial and necessary to consolidate the disorganised and disparate range of alternative culturally-orientated approaches under a single and unified brand, in order to gain visibility and credibility in the consumer research 
field. Bode and Ostergaard (2013) pinpoint that to achieve a move from a marginal position to one where institutional legitimacy and power remains a central aspiration and motivation for CCT. Although some might reasonably argue that CCT remains a relatively marginal and marginalised part of the consumer research academy, its advocates contend that researchers following this style of research would be even less visible if not for the existence of a shared and otherwise recognisable CCT brand.

Much of the discussion from within the CCT community since 2005 has been about the consequences and legitimacy of this attempt to progress a more formal union of cultural consumer research under the banner of CCT as a means to maintain a viable alternative to mainstream approaches (Cova 2009). The 2013 collection in Marketing Theory is the latest contribution to this discussion, and it is not the first occasion when the designers of CCT have made additional interventions and clarifications in response to critical objections from within the interpretive consumer research community. While definitional issues and academic politics are no doubt relevant to understanding the rise of CCT, it is important to not lose sight of the fact that the fundamental justification that Arnould and Thompson gave for imagining CCT into existence in the first place is an institutional one. This is implied in the original 2005 paper, stated in more explicit terms in their subsequent 2007 elaboration, and then recently restated in Thompson et al (2013). CCT was not, and is not, primarily a theory, not even a set of 'theoretics' but rather an institutional intervention aimed at achieving institutional aims.

Our main intention here is to highlight and critically discuss some aspects of the underlying institutional logic of CCT, and by doing so identify some of the reasons why many of its institutional aims and goals might be difficult to achieve despite on-going efforts to broaden and adapt the approach. Arguably the most important institutional aim of CCT is to provide a coherent and influential countervailing alternative in a consumer research academy that is understood to be dominated by the micro-economic and cognitive psychological paradigm. One reason why this aim will be difficult to achieve is not because paradigm dominance is overstated or misrepresented. Indeed there is more than sufficient evidence to support the claim made by CCT researchers that such paradigm preferences do prevail in the consumer research academy (AlShebil 2007). The reason why it might be difficult to achieve is the unwillingness or inability to see the ideological and historical circumstances in which CCT (and its predecessor movements) came about. Much greater consideration of these ideological and historical circumstances is needed in order to fully understand actual institutional potential and likely outcomes. The continued emphasis on paradigm divisions which are so central to the justification of CCT serves only to frame the discussion as one that primarily concerns intercommunity politics and power within the consumer research academy and between some of its factions and sub-groupings (CoskunerBalli 2013). Preoccupation with paradigm differences diverts critical gaze away from the many institutional commonalities and values shared by CCT and the dominant paradigm, as well as overshadowing some of the institutional limitations of CCT itself that result from the lack of reflexivity.

\section{Ideology and CCT}

The very fact that CCT has been able to emerge so successfully and so quickly since 2005, in what was an otherwise generally hostile and disinterested marketing mainstream, reveals something significant about CCT and the broader interpretivist tradition in consumer research. Here we will show how, when viewed in ideological terms, these apparently oppositional approaches are far closer, far more compatible and far more consistent with a 
broadly shared ideological commitment common to marketing academia than might otherwise be expected. This commitment essentially concerns a shared belief in the importance of consumption as the foundation in personal, social, economic and cultural life, the centrality of consumer as an active subject (agent), and the notion that the market offers a legitimate (if not the most legitimate) context through which individuals should seek to explore, identify and experience the world around them. The term that is most frequently used to describe this ideology today is neo-liberalism which, according to Harvey (2005: 3):

"It holds that the social good will be maximized by maximizing the reach and frequency of market transactions, and it seeks to bring all human action into the domain of the market."

It is beyond the scope of this paper to provide even a summary outline of the characteristics of neoliberalism and its critique. The analysis of neoliberalism and its consequences is a major concern for entire streams of social theory, social analysis, political philosophy and economics, as well as many other areas of intellectual enquiry. Arguments about neoliberalism transcend academic, professional, public and popular discourses, which have been greatly amplified by the events leading up to the financial collapse in 2008 and the policy responses to the crisis since. It is certainly fair to state that the term neoliberalism is generally used in the negative to refer to the damaging effects of modern forms of capitalism and the inequalities, crises and social destruction that its critics attribute to the implementation of neoliberal policies (see Harvey 2005, 2011; Chomsky, 2011; Crouch 2011; Gray 2009; Rodrick 2008).

For the purposes of this discussion neoliberalism is taken as a reasonably stable theory of political economic practices for which there is a broad consensus about what constitutes its main ideological composition. A core idea in neoliberal thought is that "human well-being can be best advanced by liberating individual entrepreneurial freedoms and skills within an institutional framework characterized by strong private property rights, free markets and free trade" (Harvey 2005:3). Neoliberal political ideology is associated with the privatization of state assets, deregulation, and the minimization of state involvement in all areas of social life other than those areas needed to secure and guarantee this economic framework (for example, legal frameworks to ensure intellectual property rights). While free market ideology has been a consistent feature of economic theory for centuries, the rise of neoliberal ideology is most commonly discussed in terms of a new political consensus that gradually emerged during the mid 1970s and early 1980s in parts of South America, the UK, the USA and elsewhere, which challenged and then rolled back many of the principles of the post-war social democratic economic orthodoxy. The election of the UK Conservative party in 1979 under the leadership of Margaret Thatcher, and the Republican presidency of Ronald Reagan in 1981, are frequently cited as important milestones in the move towards the institution of neoliberal politics and economics (Adonis, 1994; Prasad, 2006; Vinen, 2010). Neoliberal ideology underpinned the mass-privatization of public utilities such as water, energy and telecommunications, as well as other state sectors including transport, education, health care, social welfare and prisons (Clarke and Pitelis, 1995; Shiva, 2002; McCarthy and Prudham, 2004).

The rise of neoliberalism at the beginning of the 1980s fundamentally alters the meaning and significance of consumption, markets and marketing. Not only did neoliberal policies literally create new markets and therefore new consumers to an order of magnitude greater than ever before, but it also (re)emphasises the central and pivotal role of the consumer interacting in private, free and competitive markets as the primary agency for 
social action and well-being. The impact of neoliberal ideology on how people understand and locate themselves, their rights and their responsibilities is irrevocably altered. As Harvey (2005: 175-176) argues:

"The impacts on political subjectivity have been huge. This is a world in which the neoliberal ethic of intense possessive individualism and financial opportunism has become the template for human personality socialisation. This is a world that has become increasingly characterised by a hedonistic culture of consumerist excess".

From the perspective of neoliberal critique there is no substantial ideological division between mainstream marketing and the alternatives offered by CCT and its interpretivist antecedents. The divisions that were highlighted by both supporters and critics of these movements can be seen as largely technical, methodological and stylistic. CCT, and its predecessor movements, were not born out of a hostile and reluctant mainstream sometime in the early 1980s as contemporary myth often portrays but are an inevitable consequence and reflection of the neoliberalization of culture and society. With the benefit of hindsight we can see that the mainstream US consumer research establishment, dominated as it was and is by a heritage in economics, cognitive and social psychology, quantitative methodologies and a fetish for managerial relevance, actually and desperately needed such a movement to occur.

This period represented a seismic change in the political economy of the US and other western democracies, involving a paradigmatic shift in the terms by which culture and consumption were understood and defined. A reflexive acknowledgment of Askegaard and Linnet's (2011) call for consumer researchers to look for the 'context of the context' is prescient here. Rather than referring back to a narrative of competing academic movements and the consequences of academic cultural turn labour movements, it is important to recognise that other factors were also at play, and that these factors might in turn have an equal if not larger effect than those relating to the specific conditions of the consumer research discipline. To illustrate let us first re-visit the CCT creation myth and from this extend our consideration of the origins and 'context' of CCT.

\section{CCT creation myth}

Coskuner-Balli (2013: 198) notes, "Over the years, the CCT community adopted discursive strategies to mobilize cultural myths. One was to brand the work offering a more appropriate definition for this research tradition". In this myth, for at least 25 years various groups of consumer researchers interested in cultural and interpretivist approaches had sought to promote alternative ways of seeking knowledge. It can be argued that these various 'cultural/interpretivist' communities did not necessarily seek out or value a common identity or group membership, explaining why CCT or a brand like it had not emerged previously. In this view the need for a statement like CCT in 2005 reflects more of a desire on the part of the established and orthodox mainstream to be able to acknowledge, understand, define and in some respects contain disparate alternative movements into a knowable, manageable and definable entity. In this regard CCT operates, both literally and critically, as a disciplinary device. Whether or not one agrees or disagrees with these types of evaluations and critiques does not detract from the fact that both advocates and critics of CCT alike all acknowledge that CCT has a back-story. This historical account, which is the narrative that describes when, how and why CCT emerged, is an important part of the discourse through which CCT is subsequently defined, explained and justified. It operates as a type of creation myth.

This myth typically starts by outlining how a small number of researchers, research streams and schools emerged in the early to mid-1980s that were quite different to the micro- 
economic and cognitive psychology inspired approaches that dominated consumer research at the time (Hirschman and Holbrook, 1982; Holbrook and Hirschman, 1982; Belk, 1984, Belk, 1987 are some of the most frequently referenced articles that represent this mythical aspect, although there are of course many, many other papers that could be referenced here). Bode and Ostergaard (2013) describe this period as one in where dissenting voices are energised into a strong sense of community and action. The reasons for the emergence of these alternative voices in consumer research are typically attributed to forces external to the discipline itself, and especially tumultuous schisms taking place across the social sciences at the time (Coskiner-Bali 2013). As a result of these transformations cultural-turn ideas and cultural-turn labour slowly and gradually establish a provisional and minority foothold in the business school, initially existing only on the 'fringes' of business school discourse. Some of these become more established than others, some grow in size and influence and others demise.

This CCT creation story has a number of characteristic features which are important to defining and accounting for the shape of the field in the present. It is important to recognise that this narrative is not particularly unique or singular. There is much intertextuality between this specific myth and similar myths in other academic communities as well other narratives that are common to this period. Nowadays similar discourses can and are routinely used to explain patterns of migration and immigration in an age characterised by globalisation, and underpin many popular narratives surrounding multiculturalism, colonialism and post-colonial narrative and critique. The myth constructs the idea of a 'dominant' mode (micro-economics and cognitive psychology in this case) which despite its overwhelming power cannot fully contain or protect itself against 'alien' and 'progressive' intrusions from beyond its borders. CCTs big 'Other', is characterised by a curious blend of omnipotence and impotence; ever powerful and dominating and yet incapable of fully preventing infiltration and invasion from forces, workers and ideas which are expected to corrode, diminish and challenge its assumed authority.

By asking a number of critical questions of myth it becomes easier to illuminate some of its ideological precepts. The first question is why would the dominant academic mode of reproduction tolerate and permit such an intrusion to occur in the first place, given that it was likely to undermine its dominant authority and power? One answer might be that the dominant mode failed to appreciate the potential significance and magnitude of the consequences that might result from the migration of cultural turn labour and ideas into marketing faculties. Another explanation could be that this opposition is somewhat over emphasised in the narrative, that the dominant mode of academic reproduction saw little or no alternative but to embrace innovations from the cultural turn or had little or no power to resist its infiltration into the field. Perhaps there was an unarticulated recognition that business schools must, however reluctantly, 'move with the times' or risk facing loss of influence, growing irrelevance and the threat of extinction. We can perhaps take heed of other mythologies and narratives here, and acknowledge that there may have been a recognition by the dominant mode of academic reproduction that if business schools failed to find a place for cultural turn labour and ideas, then influences over cultural and sociological discourses of marketing and consumption might be lost to competing academic institutions and communities. Marketing departments have no natural monopoly over consumer and marketing discourse and we might reasonably speculate that the prospect of organisations and consultancies deciding to commission advice from (and locate their research budgets with) scores of anthropologists, sociologists and other pools of cultural turn labour would have instilled a deep sense of foreboding and unease in the boardrooms of business school faculties across the US and beyond. If one were transported back to the late 1970s and asked to 
imagine what a future neoliberal sociology might look like we might expect to see outlined something that shared many of the features and characteristics of Consumer Culture Theory (CCT).

As with many myths, a descriptive analysis of the CCT creation narrative reveals a number of unresolvable questions and ambiguities as well as highlighting associations with broader discourses of the period. But myths such as these also reveal those aspects of the cultural discourse which are obscured as a consequence of other aspects being highlighted. In the CCT myth primacy is given to movements and changes in academic discourse, practices and politics rather than to other possible accounts and explanations. By doing so CCT is positioned as an inevitable intellectual response to broader social and cultural changes taking place at the time. An alternative interpretation would be that CCT (and its predecessor movements) were/are primarily a product of these social and cultural changes rather than a means to comment on them. CCT (and its predecessors) is fundamentally different to the antecedent academic conditions and movements that feature in the creation myth, because it actually comes into existence at this particular time. CCT is not therefore a response to broader social and cultural changes but a product of them. Unlike on-going research streams in sociology and social theory for example which pre-date this moment and are then analysed as adapting to emerging social and cultural conditions, CCT is produced by and as a result of these conditions. A key question that does not feature especially prominently in CCT narratives is whether the emergence of predecessor CCT movements in the early to mid 1980s might, at least partly, be due to factors other than changes in the academic landscape that were responding to emerging social and cultural changes. Were there other institutional reasons that might account not only for the emergence of CCT, but also for its essential formulation and subsequent character?

\section{Further consideration of 'context'}

To begin we might first consider the origins and 'context' of what is arguably one of the most seminal and foundational research papers to the entire cultural turn in consumer research. It is not, for instance, purely coincidental that Morris Holbrook and Elizabeth Hirschman were working to alert the consumer research academy to the need for an expanded consumer concept (with fantasy, feeling and fun) at the same time that a Republican led US administration were embarking on a program of massive tax cuts to stimulate the economy, and pursuing policies that would hopefully see less government interference in people's lives. This is not to say of course that all cultural turn consumer researchers at this time must have supported the Republican Party or that they were advocates of Reagan's administration and policies. Indeed, one of the most lasting achievements of these political initiatives was to shift the political centre ground to the right. As a result subsequent political administrations that were nominally and historically more orientated or open to social democratic if not leftleaning policies were refashioned in such a way to fully embrace policies that were largely, if not entirely, consistent with neoliberal ideology. Obvious examples include the New-Labour movement in the UK under Blair and the policy initiatives put in place by the Democrats under the Clinton administration. For many critics this generation of governments probably did more than those that had preceded them in terms of actually realising neoliberal policies, a trend that arguably continues today.

The material consequence of these policy initiatives provided a much elevated position and significance to consumption as a structural condition of the US economy, whereby spending decisions that had been a matter of public and state control were transferred into the realm of the private market. Whether or not it appeals to consumer 
researchers political sensibilities or not is therefore largely irrelevant here. What is significant is that it is virtually inconceivable to imagine the historical evolution of consumer research, and cultural-turn consumer research in particular, independently of the political culture of the period. And yet the creation myths of CCT rarely acknowledge this 'context' at all. In their 2013 defence of CCT for example, Thompson et al (2013:155) state:

"This [CCT] ontological formulation significantly diverged from the view of the consumer as a utility maximizing, information aggregator, which then held sway, and to a remarkable degree still does in the marketing and consumer behavior fields. And it further challenged the idea that the ontological domain of consumer research should be limited to prepurchase decision making and buyer behavior and, instead, argued that consumer researchers should study a broader range of consumption experiences and practices (Belk, 1987; Holbrook, 1987).”

The context that is missing from the CCT creation myth is the source of the "broader range of consumption experiences and practices". At best we might say that CCT myths provide limited critical attention to this issue and at worst that they it institutionally ignored altogether.

The position of CCT is best understood through a narrative of discovery, in which pioneering individuals are celebrated as discovering realms of consumption that were previously unknown but had nevertheless existed undiscovered. The most illustrative example of this is the central place that the naturalistic consumer culture Odyssey is given in the mythology of CCT (Belk 1991). Of course the participants themselves can be identified as a primary source of myth making here as evidenced by the language and discourse that they themselves use to describe the research programme in explicitly classical mythological terms. In addition to the researchers own intentionality in terms of myth (re)production, the idea of setting off, into the American dessert/wilderness to find something newer, truer (if not a better way of life then a better way of consumer research) speaks to well recognised mythical trope, which although not unique to the USA by any means has a certain unique relevance in the context of USA and its modern identity as a nation. Intentionally or otherwise, those researchers who undertook the Odyssey were pioneers of neoliberal ideology, because it was through their no doubt well intentioned research objectives, and others like them, that the expansion of the disciplinary space of consumer research was achieved. Both metaphorically and literally the Odyssey sought to seek out and explore strange new worlds of consumption, to seek out new consumer lifestyles and new consumer cultures.

\section{Ideologies and subjectivities - the consumer subject}

The most sustained and widespread criticism of CCT focuses on a perception that it has a tendency to over signify consumer subjectivities, or what Thompson et al (2013) refer to as the humanistic/experientialist convention or system (Askegaard and Linnet 2011). In this dominant brand of CCT consumer agency is afforded an especially central position in accounting for consumer culture phenomena. Moisander et al. (2009) provide a detailed and thorough critique of this tendency, commenting:

"...it is necessary for consumer researchers to reject or at least problematize the overly individualistic view on human agency that characterizes much of consumer research. It is important to recognize, in line with post-structuralist conceptions of power, the significance of cultural conditions of possibility in guiding and 
constraining consumers' ways of being and acting in the world." (Moisander et al. 2009)

CCT defenders and apologists acknowledge that while CCT research may have had a tendency towards individualized accounts of consumers the idea that all or the majority of CCT research was conducted in these terms is overstated and is now a largely historical artefact that has been progressed beyond. In their 2013 remark Thompson et al. (2013) address this criticism head on and state that there are understandable institutional and pragmatic reasons why this emphasis features so prominently in the field but, as with their articulation of the creation narrative of CCT, these forces are framed as being largely internal to the academic discourse itself. But despite proclamations and protestations that CCT need not (and does not) over signify the consumer subject, there is nevertheless a legitimate sense that the movement has a particular relation to the consumer subject that is not present in other marketing sub-disciplines and communities. Whatever the CCT canon may claim, there remains a general feeling that CCT can never fully and totally accept Badje's (2013:229) Actor-Network-Theory informed interpretation that "there is no 'finished', durable 'consumer' that can exist outside of the patterned relations between people, objects and meanings that construct particular subjects, objects, spaces and times". In the most basic of terms we might ask whether it is even theoretically or hypothetically possible to conceive of cultural turn (now CCT type research)without some notion of the consumer that is not somehow already pre-understood, prefigured and conceptually loaded.

But while the argument over subjectivity and the hyper individualised subject is a relevant one, and well worth detailed consideration, it also raises a real danger that the more central question about why this should be the case, and why this is overlooked and marginalised in the our-re-evaluations of CCT. Cultural-turn research was revolutionary and transformative because it did exactly what these critics say CCT now does, but which CCT advocates are eager to downplay. Cultural Turn research elevated consumption and by direct implication - consumers - as the primary site of social and cultural action because this was the primary purpose and substance upon which its neoliberal ideological roots were founded. This is after all one of the most important and central features of neoliberal ideology - that individuals, acting in their own private self-interest is the most efficient, just and legitimate basis for social and economic organisation. If one accepts the premise that markets rather than states are the better organising principle for resource allocation and value creation, and that private rather than public interests should be primary, it logically and necessarily follows that the actions of individuals rather than collective actions should become emphasised and that consumption (as individual choice and preferences) should emerge as a primary site of action. It really should be no surprise to find that when taxes and government were cut, state owned enterprises were privatized and markets were deregulated, one consequence was that people experience more aspects of daily life as choice making individual consumers, that more aspects of economic activity are mediated via commodity relations and markets appear to be free and liberated contexts in which to pursue and enact newly possible market-type behaviours and subjectivities. Furthermore, responses from CCT authorities, either that (a) such analyses may have been more relevant in the past but are no longer, or (b) that this was never the case, serves only to further obscure the ideological basis of the CCT project and dilute its potential contribution.

\section{The neoliberal sentiment}

To further qualify this perspective it is important to restate that an explicit recognition of $\mathrm{CCT}$ as a form of neoliberal ideology need not automatically imply a critique of CCT 
researchers. This CCT ideology is not about 'lying in the guise of truth'. It may or may not be case than many CCT researchers are, at a fundamental level, comfortable and supportive of neo-liberal ideology and aims in this regard, believing that consumer culture and consumercapitalism offer the 'best of all possible worlds'. Contemporary theories of ideology do not identify any contradictions between ideology and what researchers might determine as the 'the truth' is this regard, a point well-articulated by Zizek:

Ideology has nothing to do with illusion, with a mistaken, distorted representation of its social content. To put it succinctly: a political standpoint can be quite accurate ('true') as to its objective content, yet thoroughly ideological; and vice versa, the idea that a political standpoint gives of its social content can prove totally wrong, yet there is nothing 'ideological' about it. (Zizek, 1999: 60)

This does not, however, in any way detract from the need to highlight possibilities around non-individuated terms, and by doing so emphasise the underlying ideological commitment among CCT towards a view of social action that is entirely consistent and compatible with a neoliberal position.

Our suggestion here is that one the most challenging objects of analysis for the CCT approach are its own neoliberal ideological precepts, if only because they are generally and easily obscured from the main focus of analysis, buried in discussions about the internal trajectory and formulation of the CCT approach and its quest for legitimacy in the institutions of consumer research. This argument is not primarily concerned about the breadth or range. $\mathrm{CCT}$ advocates typically respond to such criticisms by rightfully pointing to the wide range of subjects, contexts and theories that CCT has been employed to investigate. While these counter arguments illustrate the diversity of CCT research they also further emphasise the ideology of the CCT discourse by demonstrating the instrumental role of CCT in universalising market and consumption based worldviews. The fact that the CCT approach can be potentially, if only hypothetically, employed as a lens through which to examine virtually any social, cultural, individual context and phenomena as Consumer Culture is testimony to this totalizing potential. For the CCT approach to engage this challenge it might prove fruitful to design research spaces where the logic of consumption can be questioned in more critical terms, perhaps examining contexts where consumption either does not, and arguably should not, be the primary unit of analysis.

Questioning the value and benefits of applying consumption and consumer culture discourse in certain settings and circumstances will enhance the potential to develop more critically reflexive awareness in CCT which if nothing else might help to sustain and extend the brand. Some of the possible theoretical and philosophical approaches that might be useful in progressing such an approach are outlined by Cova et al (2013), although in many discussions on neoliberalism writers express considerable scepticism over the capacity for universities, themselves weakened by the implementation of neoliberal policies, to contribute in any significant way to this effort (for example, Harvey 2011: 239).

It is important to state that the perspective developed here does not impose particular political values on CCT or on CCT researchers, and acknowledging some of the neoliberal ideological values in CCT should not be taken as a prerequisite to either critique or accept neoliberal politics. Rather to have greater awareness and understanding of some of these neoliberal ideological underpinnings does, however, invite researchers to consider the extent to which it is accurate and helpful to continue to define and understand CCT as an oppositional/alternative approach in consumer research. 
While the majority of writing on neoliberalism and its consequences are generally critical and are often based on theory and philosophy that is critical of modern capitalism (Rayack, 1986; Peet, 2009; Hobsbawm, 2011) this should not detract from the importance of analysing consumer culture from a range of different perspectives. One of the characteristic features of much of the critical work on (or against) neoliberalism is that it tends to under value consumption and the role that it plays in many people's lives. Much of the genre is characterised by production orientated forms of analysis in which questions and debates regarding labour and capital overshadow complex and nuanced ideas about consumption and culture. In short, if CCT is guilty of reifying the consumer as its 'hero in history' most other theoretical traditions are equally guilty of casting the consumer as victim or villain, removing or marginalising the consumer from alternative histories and myths

Discussions about the consequences of neoliberalism would be enhanced by more sophisticated representations of consumer culture and consumer behaviour, but CCT can only hope to achieve some of its institutional aims and preoccupations if it is first prepared to first explicitly acknowledge its own ideological underpinnings as the basis of critique. As the many qualified documentary accounts have shown, the emergence of CCT as an academic sub-community in the marketing faculty is in itself an interesting case study on the origins, legitimisation and institutionalisation of academic paradigms. Part of the reason why CCT emerged when and as it did are closely linked to the academic zeitgeist but an equally important cause can be identified as the wave of financialization that occurred through the 1970s which later underpinned the subsequent acceptance and adoption of neoliberal ideology and policies.

\section{References}

Adonis, A. (1994) A Conservative revolution?: the Thatcher - Reagan decade in perspective. Manchester: Manchester University Press.

Alshebil, S. (2007) Are "Paradigms Lost" in Marketing? Some Twenty Years Later...: A Content Analysis, Advances in Consumer Research, 34, 435.

Arnould, E.J. and Thompson, C.J. (2005) 'Consumer Culture Theory (CCT): Twenty Years of Research', Journal of Consumer Research 31: 868-82.

Arnould, E.J. and Thompson, C.J. (2007) 'Consumer Culture Theory (and We Really Mean Theoretics):Dilemmas and Opportunities Posed by an Academic Branding Strategy', in R. Belk and J. F. Sherry, Jr (eds) Consumer Culture Theory, Vol. 11 of Research in Consumer Behavior, pp. 3-22. Oxford, UK: Elsevier.

Askegaard, S. and Linnet, J.T. (2011) 'Towards an Epistemology of Consumer Culture Theory: Phenomenology and the Context of Context', Marketing Theory 11: 381-04.

Bajde, D. (2013) Consumer Culture theory (re)visits actor network theory: Flattening consumption studies, Marketing Theory, 13(2), 227-242

Belk, R.W. (1984) 'Manifesto for a Consumer Behavior of Consumer Behavior', in P. F. Anderson and M. J. Ryan (eds) 1984 AMA Winter Educators' Conference: Scientific Method in Marketing, pp. 163-67. Chicago, IL:AMA. 
Belk, R.W. (1986) 'What Should ACR Want to Be When It Grows Up?', in R.J. Lutz (ed) Advances in Consumer Research. Volume 13, pp. 423-24. Provo, UT: Association for Consumer Research.

Belk, R.W. (1988) 'Possessions and the Extended Self', Journal of Consumer Research 15: 139-68.

Belk, R.W. (1991) Naturalistic Research from the Consumer Behavior Odyssey, Provo, UT: Association for Consumer Research Provo.

Bode, M. and Ostergaard, P. (2013) 'The wild and wacky worlds of consumer oddballs': Analyzing the manifestary context of consumer culture theory, Marketing Theory, 13(2), 175-192.

Chomsky, N. (2011) Profit Over People: Neoliberalism \& Global Order. New York: Seven Stories Press.

Clarke, T. and Pitelis, C. (1995) The Political Economy of Privitization. London and New York: Routlegde.

Crouch, C. (2011) The Strange Non-Death of Neoliberalism. Cambridge: Polity Press

Coskiner-Balli (2013) Market practices of legitimization: Insights from Consumer Culture Theory, Marketing Theory 13(2), 193-211.

Cova, B., Ford, D. and Salle, R. (2009) 'Academic Brands and their Impact on Scientific Endeavour: The Case of Business Market Research and Researchers', Industrial Marketing Management 38(6): 570-76.

Cova, B. Maclaren, P., and Bradshaw, A. (2013) Rethinking Consumer Culture Theory from the postmodern to the communist horizon, Marketing Theory 13(2), 213-225,

Gray, J. (2009) False Dawn: The Delusions of Global Capitalism. London: Granta Publications.

Harvey, D (2005) A Brief History of Neoliberalism. Oxford: Oxford University Press

Harvey, D. (2011) The Enigma of Capital. London: Profile Books.

Hobsbawm, E. (2011) How to change the world: tales of Marx and Marxism. London: Abacus.

Hirschman, E.C. and Holbrook, M.B. (1982) Hedonic Consumption: Emerging Concepts, Methods and Propositions, Journal of Marketing, 46(3), 92-01.

Holbrook, M.B. and Hirschman, E.C. (1981) 'Symbolic Consumer Behavior: An Introduction', in E. C. Hirschman and M. B. Holbrook (eds) Symbolic Consumer Behavior, pp. 1-2. Ann Arbor, MI: Association for Consumer Research.

McCarthy, J. and Prudham, S. (2004) Neoliberal nature and the nature of neoliberalism. Geoforum 35(3), 275-283. 
Moisander, J., Valtonen, A. and Histo, H. (2009) Personal Interviews in Cultural Consumer Research, Consumption, Markets and Culture 12(4), 329-48.

Peet, R. (2009) Unholy Trinity: The IMF, World Bank and WTO. (2 ${ }^{\text {nd }}$ ed) London: Zed Books.

Prasad, M. (2010) The politics of free markets: the rise of neoliberalism economic policies in Britain, France, Germany and the United States. Chicago: University of Chicago Press.

Rayack, E. (1986) Not so free to choose: the political economy of Milton Friedman and Ronald Reagan. Connecticut: Praeger.

Rodrik, D. (2008) One economics, many recipes: Globalization, institutions and economic growth. New York: Princeton University Press.

Shiva, V. (2002) Water Wars: Privatization, Pollution and Profit. South End Press:

Cambridge Massachusetts

Thompson, C.J., Arnold, C. and Giesler, M. (2013) Discursivity, difference, and disruption: Genealogical reflections on the consumer culture theory heteroglossia, Marketing Theory, 13(2), 149-174.

Vinen, R. (2010) Thatcher's Britain: the politics and social upheaval of the 1980s. London: Pocket Books.

Zizek, S. (1999) The Spectre of Ideology, in E.Wright and E.Wright (eds.) The Zizek Reader, Oxford: Blackwell. 